\title{
Informe de participación en la Third International Barcode of life Conference, México DF, del 7 al 13 de noviembre de 2009
}

Lucía Páiz Medina

Centro de Biología Molecular, Facultad de Ciencia, Tecnología y Ambiente, Universidad Centroamericana, Managua.

\section{2}

\section{Revisión general del tema a nivel mundial}

La Third International Barcode of Life Conference se llevó a cabo en la Ciudad de México del 7 al 13 de noviembre de 2009. Nicaragua fue representada por una investigadora

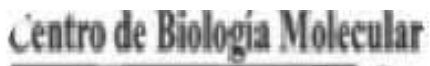
del Centro de Biología Molecular de la Universidad Centroamericana.

DNA barcoding es una nueva técnica para realizar estudios taxonómicos. El DNA Barcode es una secuencia corta y estandarizada de $\mathrm{ADN}$ del gen $\mathrm{COI}$-que ha sido muy estudiado, principalmente en animales-, que permite identificar especies utilizando técnicas moleculares no destructivas pues se necesitan pequeñas cantidades de tejido.

En la Conferencia se abarcaron diferentes aspectos en torno al Barcode of Life, entre los más relevantes están:

1. La iniciativa Barcode of Life ha tenido una gran aceptación en muchos países, principalmente, Canadá, Estados Unidos, Reino Unido, Taiwán, India y Argentina.

2. Canadá lleva la vanguardia en proyectos Barcoding, sin embargo muchos de sus especímenes no son nativos, sino colecciones de otros países, en muchos casos latinoamericanos.

3. Mundialmente los taxa que presentan mayor número de registros en BOLD (Barcode of life Data-System) y mayor número de proyectos son: peces, aves e insectos (Lepidóptera).

4. La iniciativa Barcode of life cuenta con el apoyo de gobiernos (principalmente canadiense), universidades, museos, reservas naturales y, además, el de Convention on Biological Diversity (CBD).

5. En torno a la iniciativa Barcode se han creado en la red distintos sitios hermanos que colaboran entre sí:Barcode of life Data-System, Canadian Centre for DNA Barcoding, Consortium for the Barcode of Life, además de campañas que se especializan en taxa 
especificas como: ALL-LEPS (mariposas), Fish-BOL (peces), ABBI (aves).

6. En Mesoamérica se han creado nodos de países en los que hay más avances en Barcoding (México y Costa Rica), con el fin de que los otros países interesados se unan a estas iniciativas.

\section{La Pre-Conferencia}

La Pre-Conferencia se llevó a cabo del 7 al 9 de noviembre. Se realizaron conferencias cortas que trataron de informar de manera general los aspectos esenciales acerca de la técnica DNA Barcoding. Se explicó en qué consiste, cuál es el gen que se utiliza, cuáles son los objetivos de utilizar Barcodes y qué beneficios ofrece. En otras sesiones se abordaron asuntos técnicos como protocolos de extracción, amplificación y secuenciación de las muestras.

En la Pre-Conferencia también se enfatizó la importancia de elaborar proyectos Barcoding a nivel mundial, ya que actualmente sólo algunos países llevan la vanguardia y esto no cumple con el objetivo principal de la técnica que es hacer una biblioteca de la vida con el mayor número de registros posibles. Referente a esto se hizo mucho énfasis también en hacer uso de BOLD para almacenar los registros que, por espécimen incluyen: secuencia COI, foto del espécimen, localización y voucher. Cada espécimen se divide en dos páginas principales: una con aspectos moleculares y otra de taxonomía general, es muy importante recalcar que es posible hacer análisis de las secuencias utilizando BOLD.

Además, en la Pre-conferencia se abordó la elaboración de solicitudes de financiamiento para proyectos DNA Barcoding.

\section{La Conferencia}

La Conferencia se llevó a cabo del 10 al 12 de noviembre. Constó de dos partes principales: por la mañana, paneles de conferencias generales en las que se presentaron principalmente resultados de estudios, de aplicaciones de Barcoding y se presentó la percepción de taxónomos tradicionales respecto a la técnica; por la tarde se realizaron varios seminarios que se dividieron por grupos de interés: peces, insectos, plantas, vectores de enfermedades y análisis de datos. La Conferencia fue muy importante ya que se pudo conocer directamente a los especialistas, intercambiar información, aclarar dudas y profundizar en aspectos relevantes sobre la técnica, y especialmente, sus aplicaciones.

\section{Situación y perspectiva del tema en Nicaragua}

Actualmente en Nicaragua la única iniciativa para trabajar con Barcodes la tiene el Centro de Biología Molecular con un proyecto sobre peces cíclidos de lagunas cratéricas. Este es un proyecto piloto en el país, con el que se han estandarizado protocolos (extracción, PCR, secuenciación) y se ha tratado de acumular la mayor cantidad de información posible sobre la técnica Barcoding, de manera que el Centro de Biología Molecular proporcione en el futuro las herramientas y el conocimiento necesario para otras instituciones que deseen realizar proyectos de este tipo. 


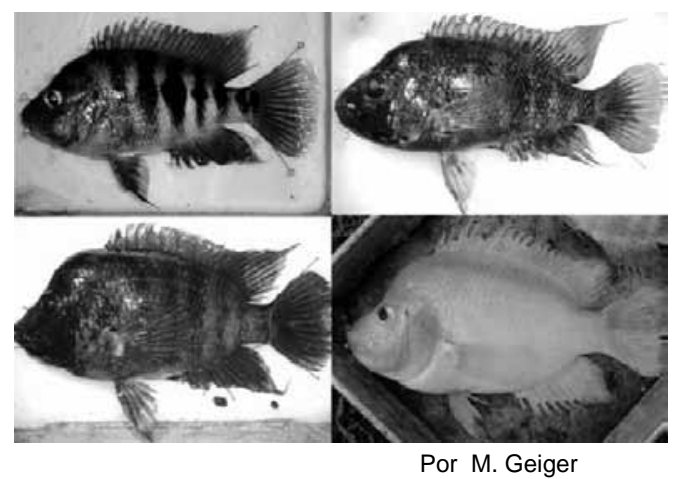

DNA Barcoding ofrece muchas aplicaciones de gran utilidad no sólo taxonómica para la identificación de especies, sino a nivel comercial y legal para regular el contrabando de especies en veda o peligro de extinción, para hacer estudios ecológicos y de biodiversidad de

104 ecosistemas amenazados, y poder compartir esta información con especialistas alrededor del mundo utilizando las facilidades del Consorcio, como BOLD.

Se considera que Nicaragua cuenta con suficiente biodiversidad para realizar un proyecto completo y de importancia a nivel nacional. El mayor problema a enfrentar es la falta de recursos tanto humanos como económicos, además de la falta de interés por parte de las autoridades de participar e invertir en proyectos de este tipo.

Aun cuando se tiene conocimiento de las limitaciones del país en relación a la investigación, es posible en el futuro, con la colaboración de especialistas en las diferentes taxa y de diferentes instituciones, lograr consolidar un Proyecto DNA Barcode, que incluya el mayor número de especímenes y registrar las especies de flora y fauna más importantes del país, contribuyendo a garantizar su preservación.

A corto plazo se considera que la participación en la Third International Barcode of Life Conference fue de suma importancia para adquirir nuevos conocimientos pero sobre todo para dejar un precedente sobre el interés de Nicaragua en unirse a la iniciativa.

\section{Enlaces importantes}

- BOLD website: www.barcodinglife.org

- $\quad$ Consortium of the Barcode of Life: www.barcoding.si.edu

- FISH-BOL: www.fishbol.org

- $\quad$ iBOL International Barcode of life: www.ibolproject.org

- CCDB Canadian Centre for DNA Barcoding: www.dnabarcoding.ca 